\title{
The role of ketotifen in the prevention of testicular damage in rats with experimental unilateral undescended testes
}

This article was published in the following Dove Press journal:

Drug Design, Development and Therapy

23 October 2014

Number of times this article has been viewed

\author{
Abdullah Acikgoz' \\ Ramazan $\mathrm{Asci}^{2}$ \\ Oguz Aydin ${ }^{3}$ \\ Hikmet Çavuș ${ }^{4}$ \\ Gamze Donmez ${ }^{5}$ \\ Recep Buyukalpelli² \\ 'Department of Urology, School \\ of Medicine, Kemerburgaz University, \\ Istanbul, Turkey; ${ }^{2}$ Department \\ of Urology, ${ }^{3}$ Department of Pathology, \\ School of Medicine, Ondokuz \\ Mayis University, Samsun, Turkey; \\ ${ }^{4}$ Department of Urology, Medical \\ Park Samsun Hospital, Samsun, \\ Turkey; ${ }^{5}$ Department of Pathology, \\ School of Medicine, Ondokuz Mayis \\ University, Samsun, Turkey
}

\begin{abstract}
The aims of this study conducted on rats were to determine mast cell (MC) proliferation on undescended testes (UDTs); whether there is a correlation between MC proliferation and testicular damage; and whether testicular damage can be prevented with administration of an MC blocker. Sixty-five newborn male rats were divided into three groups. During the neonatal period, unilateral UDTs were experimentally induced in Group 2 and Group 3. The rats in Group 3 were given $1 \mathrm{mg} / \mathrm{kg} /$ day ketotifen orally until the end of the study. Groups 2 $(n=30)$ and $3(n=15)$ were divided into groups of ten and five rats, respectively, each of which underwent bilateral orchiectomy in either the prepubertal, pubertal, or adult period. Group 1 $(n=15)$ underwent a sham operation followed by bilateral orchiectomy, with five rats in each of the prepubertal, pubertal, and adult periods. Testicular MCs in the interstitial and subtubular areas, biopsy scores, interstitial connective tissue, seminiferous tubule (ST) diameters, and the basement membrane thickness of STs were evaluated. In Group 2 the ST diameters in the UDTs decreased, the number of MCs in the interstitial and subtubular areas increased, ST basement membranes thickened, and spermatogenesis decreased. The number of MCs in the interstitial and subtubular areas of the descended testes increased and spermatogenesis decreased. In Group 3, the number of MCs in the interstitial and subtubular areas decreased. In unilateral UDTs, the number of MCs in the interstitial and subtubular areas increased in both testes. Fibrosis developed in the ST basement membranes and interstitial areas, and spermatogenesis deteriorated. Testicular fibrosis may be prevented with administration of an MC blocker.
\end{abstract}

Keywords: rat, unilateral undescended testis, MC, spermatogenesis, atrophic testis

\section{Introduction}

Cryptorchidism is the most common endocrine disorder in male children. ${ }^{1}$ An undescended testis (UDT) occurs in approximately $3.7 \%$ of boys at birth, and $1.1 \%$ will still have an UDT at 1 year of age. ${ }^{2}$ If a testis fails to descend on its own by 9 months of age, then surgery is recommended. ${ }^{3}$ Fibrosis of the UDT increases significantly after 1 year. ${ }^{4,5}$ As fibrosis replaces the functional parenchyma of the affected testis, there is simultaneously an age-related decrease in germ cell number. There is contradictory evidence as to whether this is a cause-effect relationship or merely an association. It is clear that fibrosis is a time-dependent consequence of untreated cryptorchidism (and possibly treated cryptorchidism), but the pathophysiology of this process is still unknown.

Mast cells (MCs) are a free cell type usually found in connective tissues, not only during specific acquired immunity responses, but also in innate immunity and tissue homeostasis and remodeling. They secrete and respond to a plethora of immune
Correspondence: Abdullah Acikgoz Department of Urology, Kemerburgaz University School of Medicine, Mahmutbey Dilmenler Caddesi, No 26, 34217 Bağcılar - İstanbul, Turkey

Tel +905334692030

Fax +9036231I 4062

Email draacikgoz@yahoo.com 
mediators, such as cytokines and chemokines. ${ }^{6} \mathrm{MCs}$ activate fibroblasts and promote collagen synthesis by producing and releasing fibrogenic substances. Tryptase, one of the principal molecules released by MCs, also significantly enhances fibroblast proliferation and collagen synthesis. ${ }^{7}$ Another mechanism by which MCs may regulate fibrosis is by activation of matrix metalloproteinases and tissue inhibitors of matrix metalloproteinases, which are active in pathways regulating growth and differentiation. ${ }^{8}$

$\mathrm{MCs}$ are found in normal human testes and are increased in number in the testes of infertile men. Increased MC numbers were found to correlate with sclerosis and fibrosis of seminiferous tubules (STs) in adults with varicoceles. ${ }^{9}$ Significant rises in interstitial and peritubular MCs have been found in adults with defective spermatogenesis. ${ }^{10}$ In these individuals, the mean numbers of total and interstitial MCs were significantly higher in cases with sclerosing histology. These data suggest that there is a correlation between MC number and fibrosis in infertile adults, but the role of MCs in cryptorchidism is unknown.

The aims of this study conducted on rats were to determine whether there is MC proliferation in undescended testes; whether there is a correlation between MC proliferation and testicular damage; and whether testicular damage can be prevented with administration of a MC blocker.

\section{Materials and methods}

The experimental protocol was approved by the Animal Care and Ethics Committee of our institution. A total of 65 newborn male Wistar rats were used in the experiments. The rats were maintained under standard rat laboratory conditions in a temperature- and light-controlled room (temperature $23^{\circ} \mathrm{C} \pm 2^{\circ} \mathrm{C}$; 16-hour:8-hour light:dark cycle). They were fed on standard rat rations and tap water. Zero- to 15-day-old rats were classified as newborn; 15- to 25-day-old rats as prepubertal; 39- to 47-day-old rats as pubertal; and rats $>120$ days old as adult. ${ }^{11}$

\section{Surgical procedures}

Unilateral cryptorchidism was induced using a previously described surgical procedure. ${ }^{12}$ In brief, the Wistar rats $(n=45)$ in the newborn period were anesthetized and, after a small incision was made in the abdomen, the gubernaculum was cut on one side to displace the testis into the abdomen. Testis descent was prevented by closure of the inguinal canal on the same side by suturing. The rats $(n=15)$ in the control group (Group 1) underwent a sham operation. At the end of the experimental period, bilateral orchiectomy was performed on all rats.

\section{Study groups \\ Group I}

As a sham group, this consisted of 15 newborn rats. This group was further subdivided into three groups ( $\mathrm{n}=5$ in each), which underwent bilateral orchiectomy in the prepubertal, pubertal, and adult period, respectively.

\section{Group 2}

This group consisted of 30 rats. After experimental unilateral cryptorchidism, this group was further subdivided into three groups ( $\mathrm{n}=10$ in each), which underwent bilateral orchiectomy in the prepubertal, pubertal, and adult period, respectively.

\section{Group 3}

This group consisted of 15 rats. After experimental unilateral cryptorchidism, MC blocker treatment $(1 \mathrm{mg} / \mathrm{kg} /$ day liquid ketotifen) was administered daily, directly into the stomach of the rats via the oral gavage technique, until the end of the study. This group was further subdivided into three groups ( $n=5$ in each), which underwent bilateral orchiectomy in the prepubertal, pubertal, and adult period, respectively.

\section{Histopathological analysis}

The testes were fixed in 10\% neutral buffered formalin solution for 24 hours and were sampled, with slices taken from the widest axis. Paraffin blocks of the samples were prepared through routine tissue follow-up procedure. Sections of 4-6 $\mu \mathrm{m}$ were cut from paraffin blocks and stained with toluidine blue, Masson's trichrome, and hematoxylin and eosin. The stained sections were evaluated under a light microscope (Olympus BX 50; Olympus Corporation, Tokyo, Japan) by a pathologist who was not informed about the operations applied to the groups.

\section{Testicular morphological analyses}

The testes removed by orchiectomy were prepared for histopathological analysis. The ST diameters of the testes were measured and the MCs in the interstitial and subtubular areas were counted. Fibrosis that had developed in the interstitial areas and the thickness of the ST basement membranes were evaluated.

\section{Spermatogenesis}

The STs were graded according to the Johnsen score. ${ }^{13}$ In this system of classification, all tubular sections in each section of the testis are evaluated systematically and each is given 
a score from 1 to 10 . Complete spermatogenesis with many spermatozoa present is evaluated as a score of $10 .{ }^{14}$

\section{MCs}

Sections stained with toluidine blue were determined under the Olympus BX 50 light microscope ( $\times 20$ magnification area $[\mathrm{HPF}]=0.44 \mathrm{~mm}^{2}$ ). MCs were seen in two different areas. MCs found beneath the seminiferous basement membrane were named subtubular MCs, and those found in the interstitium were named interstitial MCs. MCs in the subtubular and interstitial areas were counted by scanning 10-32 fields through an HPF in accordance with the size of the tissue, and were calculated as the mean number of MCs in one HPF.

\section{Interstitial connective tissue analysis}

The methods for characterization of fibrosis has been validated and previously described. ${ }^{15}$ Briefly, they were stained with hematoxylin and eosin and Masson's trichrome. Fibrosis was categorized by the percentage of fibrosis present, as follows:

- (-): no fibrosis in interstitial space $(<5 \%)$;

- (+): mild fibrosis in connective tissue $(6 \%-25 \%)$;

- $(++)$ : moderate fibrosis in connective tissue $(26 \%-50 \%)$; and

- $(+++)$ : severe fibrosis in connective tissue $(>50 \%)$.

\section{ST basement membrane thickness}

The thickness of the Masson's trichrome-stained slices of ST basement membranes was evaluated qualitatively. Results were expressed as follows:

- (-): no thickening in basement membrane;

- (+): mild thickening in basement membrane;

- $(++)$ : moderate thickening in basement membrane; and

- $(+++)$ : severe thickening in basement membrane.

\section{ST diameters}

Images of STs in the sections stained with hematoxylin and eosin were magnified $10 \times$ under a light microscope (Axiophot; Carl Zeiss Meditec AG, Jena, Germany) and were transferred to a computer with a digital camera (Insight Diagnostic Instrument, USA) attached to the microscope. In the digitalized images of each section, diameters of the 25 most circular STs were measured with morphometry software and an image analysis program (Samba 2005; Samba Technologies, Grenoble, France). The mean ST diameter was calculated for each testis.

\section{Statistical analysis}

Since the data did not comply with normal distribution, logarithmic conversion was used. Therefore, all the comparisons among the groups and within the groups were performed using nonparametric tests. Intragroup variables were compared primarily with Kruskal-Wallis variance analysis. Paired same-group comparisons were performed with the Mann-Whitney $U$-test.

Data for the right and left testes of rats in the prepubertal, pubertal, and adult periods in each group were compared with the Wilcoxon matched-pairs test. Spearman's correlation analysis was used to determine whether there was a correlation between the number of MCs and the thickness of the ST basement membrane and the increased rate of interstitial connective tissue, and between the number of MCs and the Johnsen score. The significance level was determined as $P \leq 0.05$.

\section{Results}

All rats were physically healthy after completion of the study.

\section{ST diameters}

The mean ST diameters are shown in Table 1. In Groups 1 and 2, the mean ST diameters of descended testes for all periods were similar $(P=0.624, P=0.391$, and $P=0.903$, respectively). In Groups 2 and 3, the mean ST diameters of descended testes for all periods were also similar $(P=0.806$, $P=0.066$, and $P=0.221$, respectively).

The mean ST diameters of undescended testes for all periods in Group 2 were smaller than those in the control group ( $P=0.002, P=0.003$, and $P=0.003$, respectively).

The mean ST diameters of undescended testes for all periods in Group 3 were smaller than those in the control group ( $P=0.016, P=0.028$, and $P=0.016$, respectively).

As can be seen in Table 1, the mean ST diameters of undescended testes in Group 3 were larger than those in Group 2 for all periods, but the differences were not statistically significant ( $P=0.327, P=0.540$, and $P=0.391$, respectively).

\section{MCs}

The numbers of interstitial and subtubular MCs in each group are shown in Table 2. In Group 2, the mean numbers of interstitial MCs of descended testes per HPF for all periods were higher than those in Group $1(P=0.010$, $P=0.010$, and $P=0.007$, respectively) (Figure 1A and B). In Group 3, the mean number of interstitial MCs per unit area in the descended testes was higher than that in the control 
Table I Diameters of seminiferous tubules (STs) in each group (mean \pm standard deviation)

\begin{tabular}{|c|c|c|}
\hline Period & $\begin{array}{l}\text { Scrotal (right) testis } \\
\text { Diameter of STs }(\mu \mathrm{m})\end{array}$ & $\begin{array}{l}\text { Abdominal (left) testis } \\
\text { Diameter of STs }(\mu \mathrm{m})\end{array}$ \\
\hline \multicolumn{3}{|c|}{ Group I (total: I 5 rats) } \\
\hline Prepubertal $(n=5)$ & $220.43 \pm 7.5$ & $218.09 \pm 8.6$ \\
\hline Pubertal $(n=5)$ & $219.01 \pm 5.8$ & $226.50 \pm 7.2$ \\
\hline Adult $(n=5)$ & $228.8 I \pm 4.8$ & $219.35 \pm 9.6$ \\
\hline \multicolumn{3}{|c|}{ Group 2 (total: 30 rats) } \\
\hline Prepubertal $(n=10)$ & $216.488 \pm 5.0$ & $|49.70| \pm 6.9$ \\
\hline Pubertal $(n=10)$ & $215.721 \pm 0.9$ & $137.478 \pm 8.6$ \\
\hline Adult $(n=10)$ & $224.250 \pm 6.6$ & | $46.449 \pm 8.7$ \\
\hline \multicolumn{3}{|c|}{ Group 3 (total: 15 rats) } \\
\hline Prepubertal $(n=5)$ & $219.54 \pm 7.5$ & $|63.48 \pm 1|$ \\
\hline Pubertal $(n=5)$ & $217.74 \pm 19$ & $162.63 \pm 24$ \\
\hline Adult $(n=5)$ & $225.98 \pm 2.3$ & $160.22 \pm 13$ \\
\hline
\end{tabular}

Notes: Group I rats received a sham operation followed by bilateral orchiectomy in one of the different periods. Group 2 rats received experimental unilateral cryptorchidism followed by bilateral orchiectomy in one of the different periods. Group 3 rats received experimental unilateral cryptorchidism and MC blocker treatment (I mg/kg/day liquid ketotifen, administered daily until the end of the study), followed by a bilateral orchiectomy in one of the different periods.

group in the prepubertal period $(P=0.011)$, but was similar in both groups in the pubertal and adult periods $(P=0.251$ and $P=0.46$, respectively). Furthermore, the mean number of interstitial MCs per unit area in descended testes in the pubertal and adult periods in Group 3 was less than that in Group 2 ( $P=0.037$ and $P=0.007$, respectively).

The mean number of interstitial MCs per unit area in undescended testes for all periods in Group 2 was higher than that in the control group $(P=0.005, P=0.002$, and $P=0.002$, respectively). The mean number of interstitial MCs per unit area in undescended testes for all periods in Group 3 was also higher than that in the control group $(P=0.009, P=0.009$, and $P=0.009$, respectively). The mean number of interstitial MCs per unit area in undescended testes in Group 3 was similar to that in Group 2 in the prepubertal period $(P=0.713)$, but was lower in Group 3 than in Group 2 in the pubertal and adult periods ( $P=0.007$ and $P=0.003$, respectively).

In Group 2, the mean number of subtubular MCs per unit area in descended testes was similar to that in Group 3 and in the control group in the prepubertal period ( $P=0.057$ and $P=0.578$, respectively); however, it was higher in Group 2 than in the control group $(P=0.005$ and $P=0.002)$ and also higher in Group 2 than in Group $3(P=0.032$ and $P=0.004)$ in the pubertal and adult periods, respectively.

Although the mean number of subtubular MCs per unit area in undescended testes in Group 2 was similar to that in

Table 2 Numbers of interstitial and subtubular mast cells in each group

\begin{tabular}{|c|c|c|c|c|}
\hline \multirow[t]{2}{*}{ Period } & \multicolumn{2}{|c|}{ Scrotal (right) testis } & \multicolumn{2}{|c|}{ Abdominal (left) testis } \\
\hline & Interstitial & Subtubular & Interstitial & Subtubular \\
\hline \multicolumn{5}{|c|}{ Group I (total: I 5 rats) } \\
\hline Prepubertal $(n=5)$ & $0.04 \pm 0.03$ & $0.05 \pm 0.007$ & $0.1 I \pm 0.04$ & $0.06 \pm 0.009$ \\
\hline Pubertal $(n=5)$ & $0.18 \pm 0.08$ & $0.05 \pm 0.008$ & $0.14 \pm 0.04$ & $0.11 \pm 0.04$ \\
\hline Adult $(n=5)$ & $0.12 \pm 0.04$ & $0.04 \pm 0.004$ & $0.12 \pm 0.04$ & $0.05 \pm 0.02$ \\
\hline \multicolumn{5}{|c|}{ Group 2 (total: 30 rats) } \\
\hline Prepubertal $(n=10)$ & $0.91 \pm 0.29$ & $0.06 \pm 0.01$ & $2.22 \pm 0.67$ & $0.32 \pm 0.07$ \\
\hline Pubertal $(n=10)$ & $0.89 \pm 0.25$ & $0.06 \pm 0.007$ & $4.47 \pm 0.89$ & $0.485 \pm 0.07$ \\
\hline Adult $(n=10)$ & $0.82 \pm 0.32$ & $0.05 \pm 0.01$ & $6.62 \pm 2.66$ & $0.687 \pm 0.13$ \\
\hline \multicolumn{5}{|c|}{ Group 3 (total: I 5 rats) } \\
\hline Prepubertal $(n=5)$ & $0.24 \pm 0.05$ & $0.04 \pm 0.03$ & $1.35 \pm 0.18$ & $0.174 \pm 0.05$ \\
\hline Pubertal $(n=5)$ & $0.28 \pm 0.05$ & $0.05 \pm 0.02$ & $1.57 \pm 0.16$ & $0.159 \pm 0.05$ \\
\hline Adult $(n=5)$ & $0.15 \pm 0.04$ & $0.05 \pm 0.009$ & $1.97 \pm 0.30$ & $0.05 \pm 0.009$ \\
\hline
\end{tabular}

Notes: Group I rats received a sham operation followed by bilateral orchiectomy in one of the different periods. Group 2 rats received experimental unilateral cryptorchidism followed by bilateral orchiectomy in one of the different periods. Group 3 rats received experimental unilateral cryptorchidism and MC blocker treatment (I mg/kg/day liquid ketotifen, administered daily until the end of the study), followed by a bilateral orchiectomy in one of the different periods. Data are shown as mean \pm standard deviation. 


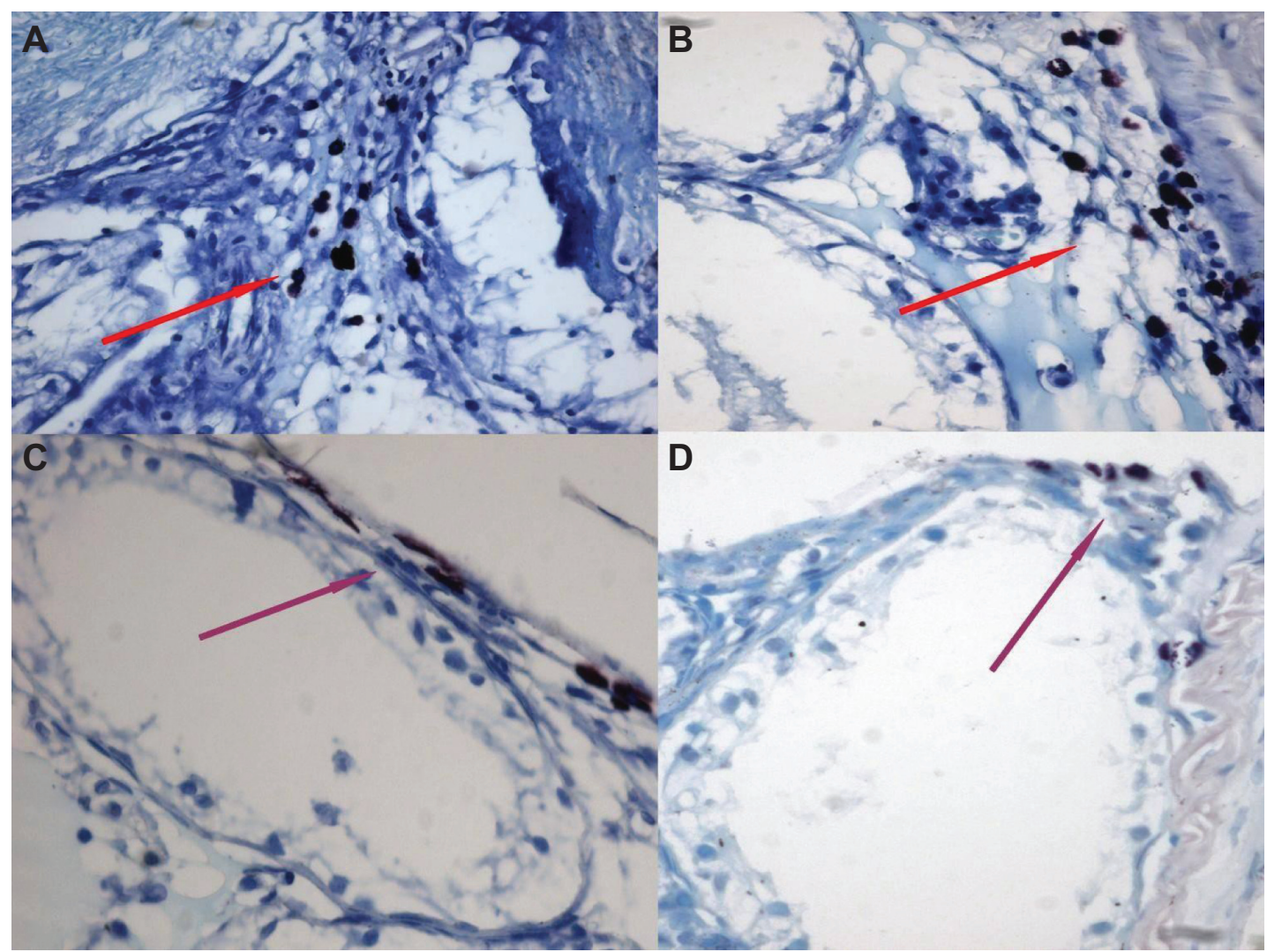

Figure I MCs shown by toluidine blue staining in the pubertal and postpubertal periods in Group 2.

Notes: (A) Interstitial MCs. (B) Interstitial MCs. (C) Subtubular MCs. (D) Subtubular MCs. Red arrows show interstitial MCs and purple arrows show subtubular MCs. Abbreviation: MCs, mast cells.

Group 3 in the prepubertal period $(P=0.297)$, it was higher in Group 2 than in Group 3 in the pubertal and adult periods ( $P=0.020$ and $P=0.002$, respectively). The mean number of subtubular MCs per unit area in undescended testes in Group 2 for all periods was higher than that in the control group ( $P=0.002, P=0.010$, and $P=0.002$, respectively). The mean number of subtubular MCs per unit area in undescended testes in Group 3 was similar to that in the control group for all periods $(P=0.251, P=0.168$, and $P=0.459$, respectively) (Figure $1 \mathrm{C}$ and $\mathrm{D}$ ).

\section{Spermatogenesis}

The mean Johnsen scores for all groups are shown in Table 3. While the mean Johnsen score of descended testes in Group 2 was similar to that in the control group in the prepubertal period $(P=0.068)$, it was lower in Group 2 than in the control group in the pubertal and adult periods $(P=0.004$ and $P=0.021$, respectively). On the other hand, the mean Johnsen score of the descended testes in Group 3 was similar to that in the control group for all periods ( $P=0.136, P=1$, and $P=0.449$, respectively). Furthermore, the mean Johnsen score of the descended testes in Group 3 was higher than that in Group 2 in the pubertal and adult periods ( $P=0.004$ and $P=0.034$, respectively).

The mean Johnsen scores of undescended testes in Group 2 and Group 3 for all periods were significantly lower than

Table 3 Johnsen scores in each group (mean \pm standard deviation)

\begin{tabular}{|c|c|c|}
\hline Period & $\begin{array}{l}\text { Scrotal (right) } \\
\text { testis }\end{array}$ & $\begin{array}{l}\text { Abdominal (left) } \\
\text { testis }\end{array}$ \\
\hline \multicolumn{3}{|c|}{ Group I (total: I 5 rats) } \\
\hline Prepubertal $(n=5)$ & 10 & 10 \\
\hline Pubertal $(n=5)$ & 10 & 10 \\
\hline Adult $(n=5)$ & $9.98 \pm 0.03$ & 10 \\
\hline \multicolumn{3}{|c|}{ Group 2 (total: 30 rats) } \\
\hline Prepubertal $(n=10)$ & $9.95 \pm 0.01$ & $2.7 \pm 0.1$ \\
\hline Pubertal $(n=10)$ & $9.92 \pm 0.02$ & $3.9 \pm 0.6$ \\
\hline Adult $(n=10)$ & $9.85 \pm 0.01$ & $3.9 \pm 0.5$ \\
\hline \multicolumn{3}{|c|}{ Group 3 (total: I 5 rats) } \\
\hline Prepubertal $(n=5)$ & $9.96 \pm 0.02$ & $2.7 \pm 0.3$ \\
\hline Pubertal $(n=5)$ & 10 & $4.3 \pm 0.3$ \\
\hline Adult $(n=5)$ & $9.93 \pm 0.03$ & $4.4 \pm 0.4$ \\
\hline
\end{tabular}

Notes: Group I rats received a sham operation followed by bilateral orchiectomy in one of the different periods. Group 2 rats received experimental unilateral cryptorchidism followed by bilateral orchiectomy in one of the different periods. Group 3 rats received experimental unilateral cryptorchidism and MC blocker treatment $(\mathrm{I} \mathrm{mg} / \mathrm{kg} /$ day liquid ketotifen, administered daily until the end of the study), followed by a bilateral orchiectomy in one of the different periods. 


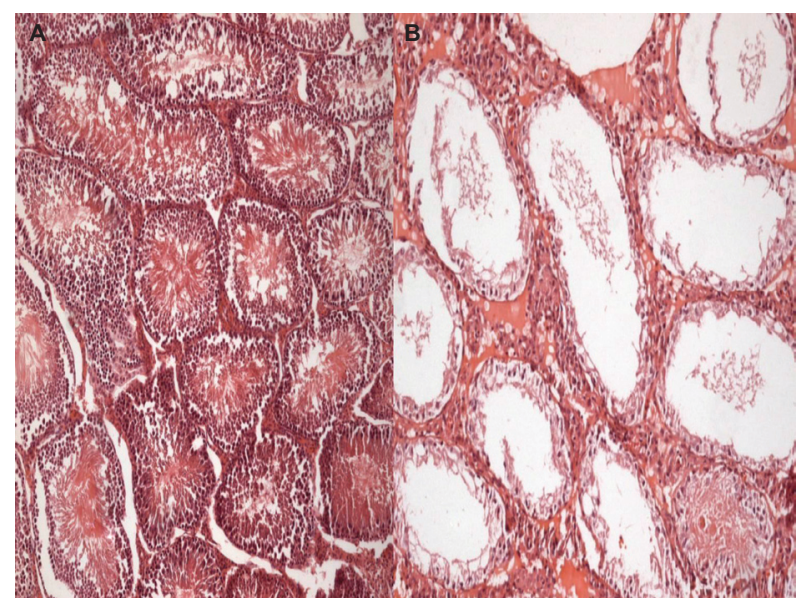

Figure 2 Johnsen score, hematoxylin and eosin staining in postpubertal periods. Notes: (A) Descended testis. Johnsen score is ten. (B) Undescended testis. Johnsen score is two.

those in the control group (Figure 2). Although the mean Johnsen score of undescended testes in Group 3 in the pubertal and adult periods was higher than that in Group 2, the differences were not statistically significant $(P=0.178$ and $P=0.421$, respectively).

\section{Interstitial connective tissue and ST basement membranes}

Interstitial connective tissues and ST basement membranes of the descended testes in Groups 2 and 3 were normal for all periods.

However, in the undescended testes of Group 2, gradual thickening of ST basement membranes and interstitial connective tissue fibrosis were observed starting from the prepubertal period (Figures 3 and 4). Interstitial connective tissues

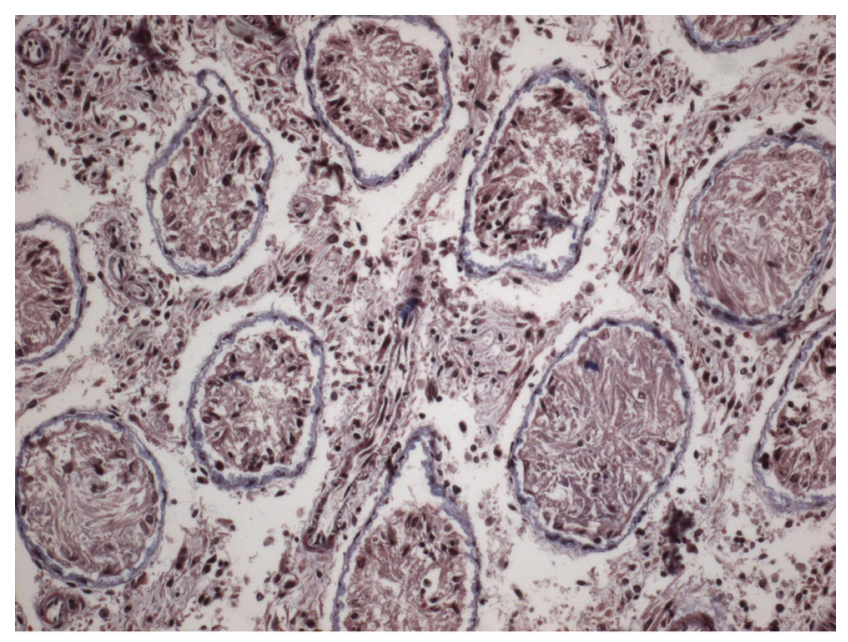

Figure 3 Interstitial fibrosis shown by Masson's trichrome staining in postpubertal periods.

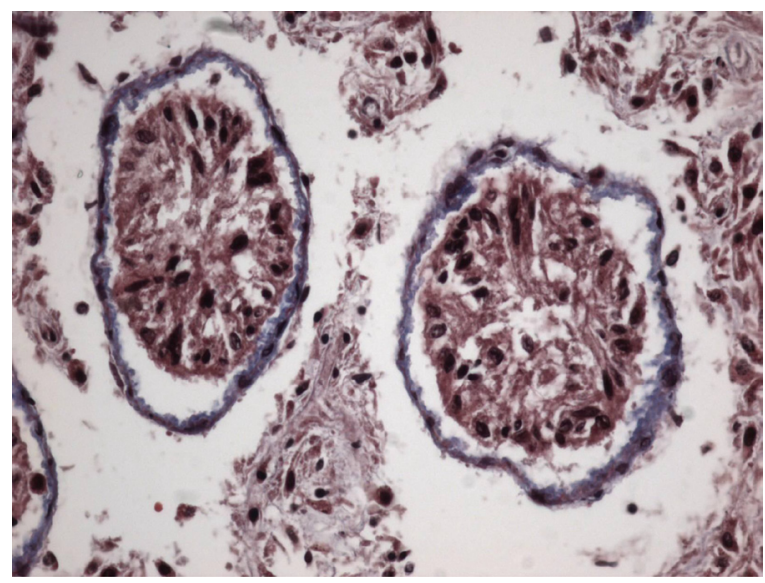

Figure 4 Basement membrane thickness shown by Masson's trichrome staining in postpubertal periods.

and ST basement membranes of the undescended testes in Group 3 were normal in the prepubertal period but, after this period, gradual thickening of the ST basement membranes and interstitial connective tissue fibrosis were observed.

In the adult period in Group 2, a very strong correlation was observed between the number of interstitial MCs and the thickness of the ST basement membrane in the undescended testes ( $P=0.001, r=0.88)$; there was also a strong correlation between the number of interstitial MCs and interstitial connective tissue fibrosis in undescended testes $(P=0.017, r=0.77)$. Furthermore, a very strong negative relationship was detected between the number of interstitial ( $P=0.000, r=-995)$ and subtubular $(P=0.003, r=-834) \mathrm{MCs}$ and the Johnsen score in undescended testes in the adult period in Group 2.

\section{Discussion}

A histometric study has shown that the number of MCs in the testes and epididymis increase slightly during infancy, decrease during childhood, and then increase again at puberty.${ }^{16} \mathrm{MCs}$ are distributed in different areas of the testis depending on the species; in the rat, they are restricted to the subalbuginea area near blood vessels, in contrast with human testes, in which they are localized in the interstitium and peritubular areas. ${ }^{17}$ In our study, MCs in both testes were found in two different areas. MCs found beneath the seminiferous basement membrane were named subtubular MCs, and those found in the interstitium were named interstitial MCs. Gaytan et al examined the effects of androgens on neonatal rat testes and found that, in control animals, MCs were exclusively located under the tunica albuginea around blood vessels. ${ }^{18}$ 
There are multiple stains available to aid in identifying MCs in human tissue. Alcian blue, toluidine blue, safranin, histamine, trypsin, and chymotrypsin are some commonly used stains. Alcian blue and toluidine blue stain acidic polysaccharides, such as those contained in MC granules, and are nonspecific. ${ }^{19}$ Safranin is a basic dye that stains some MC granules, and it is often used as a counterstain and with Alcian blue. Tryptase is a protein contained in the granules of all MCs, but chymase is not always present and therefore less sensitive. ${ }^{20}$ With the use of tryptase staining, the number of interstitial and peritubular MCs in the testes of infertile males has been shown to increase. ${ }^{10}$ In our study, tryptase staining was applied first to paraffin blocks of the samples, but the MCs were not stained with tryptase because the activity of tryptase in rodent MCs is low and limited. ${ }^{21}$ Paraffin blocks of samples were then stained with toluidine blue, which has been shown to be effective in staining atypical or mucosal MCs. In the microscopic evaluation of the toluidine blue-stained sections, MCs were differentiated by the existence of reddish-purple metachromatic granules.

Mechlin et al found that MCs were present in prepubertal cryptorchid testes. ${ }^{22}$ The number of MCs was highest in younger patients. The MCs in their study were found in the interstitium and peritubular regions, which is abnormal.

In Group 2, we found that the mean numbers of interstitial and subtubular MCs in both testes for all periods were higher than in other groups. There was a significant association between period of life and MC number. Mechlin et al did not see a statistically significant correlation between the age and the mean $\mathrm{MC}$ number. ${ }^{22}$

In the group given $\mathrm{MC}$ blocker, there was an increase in the number of subtubular and interstitial MCs in both testes in the prepubertal period, but a decrease in the number of MCs in both testes was observed in the pubertal and adult periods. This result indicates that, in cases of unilateral undescended testes, the proliferation of MCs in both testes can be prevented with administration of a MC blocker.

Several reports have associated an increased number of MCs with male infertility. ${ }^{23-25}$ In cases of idiopathic male infertility, Hashimoto et $\mathrm{al}^{26}$ and Nagai et $\mathrm{al}^{27}$ demonstrated increased MCs in the lamina propria of STs, and observed a rise in chondroitin sulfate-positive MCs. Hussein et al associated abnormal spermatogenesis with increased numbers of MCs. ${ }^{28}$ Albrecht et al concluded that human peritubular cells are a novel model for investigating paracrine, including MC-initiated, interactions in the human testis that allows the study of fibrotic processes underlying male idiopathic infertility. ${ }^{29}$
With the increase in the number and activation of MCs, mediators such as histamine, serotonin, and heparin present in the secretion granules, tryptase and chymase enzymes, and cytokines such as transforming growth factor beta, transforming growth factor alpha, interleukin-1, -3, -4, -6, $-9,-13$, and nerve growth factor lead to fibroblast proliferation and activation, capillary proliferation, and lymphocyte infiltration. ${ }^{30,31}$ Consequently, type 1 collagen synthesis increases and fibrosis develops. Adam et al demonstrated that $\mathrm{MC}$ tryptase stimulates production of decorin by human testicular peritubular cells. These authors suggested that one possible role of decorin in male infertility is to prevent growth factor signaling, and demonstrated that increases in testicular decorin found in male infertility are a consequence of actions of MC-derived tryptase. ${ }^{32}$ On the basis of these data, it has been suggested that testicular MCs can be associated with male infertility. ${ }^{10}$ Damage to the interstitial and peritubular areas, STs, and germ cells of both testes can be prevented by blocking the proliferation and activation of MCs.

It is a fact that spermatogenetic activity decreases in undescended testes. ${ }^{30}$ In our study, the mean Johnsen scores for the undescended testes of the rats in Groups 2 and 3 were lower than those in the control group. Although the mean Johnsen scores for undescended testes of the rats in Group 3 were higher than those in Group 2, the differences were not statistically significant. Furthermore, a strong negative correlation was observed between the numbers of interstitial and subtubular MCs and Johnsen scores of adult rats not given $\mathrm{MC}$ blocker.

It has been claimed that these autoimmune reactions in the UDT also affect the contralateral descended testis. ${ }^{33}$ In cases of unilateral undescended testes, spermatogenetic activity of the contralateral descended testis is often abnormal. ${ }^{33}$ In a similar clinical study performed by Huff et al it was demonstrated that the defect in the transformation of spermatogonia into primary spermatocytes during the prepubertal period leads to a decrease in the population of germ cells in the descended testis. ${ }^{34}$ Similarly, in our experimental study, we observed that spermatogenetic activity of the descended testes in the group not given MC blocker permanently decreased after the prepubertal period. However, the spermatogenesis of the descended testes in the group given MC blocker remained stable in all periods. In our study, we found the numbers of interstitial and subtubular MCs in the contralateral descended testes in the group given MC blocker to be significantly higher than those in the control group. Increasing $\mathrm{MC}$ number may be responsible for affecting the 
contralateral testis. We also observed that the number of interstitial and subtubular MCs in the contralateral descended testes in rats given $\mathrm{MC}$ blocker decreased starting from the prepubertal period. In cases of unilateral undescended testes, contralateral descended testis function may be protected with use of a MC blocker before and after orchidopexy, thus fertility potential can be saved.

It has been reported that the ST diameters of unilateral undescended testes in adult rats decrease when compared with those of the descended testes and control group. ${ }^{35,36}$ In our study, it was also observed that the ST diameters of the undescended testes decreased in the prepubertal, pubertal, and adult periods. The mean ST diameters of the undescended testes in rats given $\mathrm{MC}$ blocker were greater than in those rats not given $\mathrm{MC}$ blocker.

The thickening in the ST basement membrane in the UDT has been reported to begin in the prepubertal period. ${ }^{37}$ Kerr et al created undescended testes in rats and observed thickening in the ST basement membranes of the undescended testes after a 7-day period. ${ }^{38}$ Biopsies of infertile male testes have revealed conformity between the fibrous thickening on the wall of the ST and an increase in the number of active MCs. ${ }^{10}$ In the current study, thickening starting from the prepubertal period was observed in the ST basement membranes of the undescended testes in rats not given MC blocker. Furthermore, it was observed that the ST basement membrane thickness had a very strong positive correlation with the number of interstitial MCs and a strong positive correlation with the number of subtubular MCs. There was also a strong correlation between the number of interstitial MCs in the undescended testes and fibrosis. Mechlin et al found that the number of MCs are inversely correlated with fibrosis. ${ }^{22}$ This is in contrast to what has been described elsewhere in human infertile adult males: in adult testes, MCs are associated with peritubular fibrosis, atrophy, and infertility. $9,10,39-41$

\section{Conclusion}

In unilateral undescended testes, the numbers of MCs in the interstitial and subtubular areas are increased. Fibrosis develops in the ST basement membranes and interstitial areas, and spermatogenesis deteriorates. A MC blocker may be used to prevent the inflammatory and fibrotic process before and after surgical treatment.

In cases of unilateral undescended testes, spermatogenetic activity of the contralateral descended testis is also affected. In the current study, it was shown that the inflammatory and fibrotic process may develop due to the increase in the number of MCs in the contralateral descended testis.
In unilateral undescended testes, it has also been thought that the fertility potential of the contralateral descended testis may be protected by the administration of MC blocker treatment. However, further clinical studies are needed to assess efficacy, safety, and optimal dosage.

\section{Disclosure}

The authors report no conflicts of interest in this work.

\section{References}

1. Thong M, Lim C, Fatimah H. Undescended testes: incidence in 1,002 consecutive male infants and outcome at 1 year of age. Pediatr Surg Int. 1998;13:37-41.

2. Berkowitz GS, Lapinski RH, Dolgin SE, Gazella JG, Bodian CA, Holzman IR. Prevalence and natural history of cryptorchidism. Pediatrics. 1993;92:44-49.

3. Gill B, Kogan S. Cryptorchidism. Current concepts. Pediatr Clin North Am. 1997;44:1211-1227.

4. Läckgren G, Plöen L. The morphology of the human undescended testis with special reference to the Sertoli cell and puberty. Int J Androl. 1984;7(1):23-38.

5. Park KH, Lee JH, Han JJ, Lee SD, Song SY. Histological evidences suggest recommending orchiopexy within the first year of life for children with unilateral inguinal cryptorchid testis. Int J Urol. 2007; 14:616-621.

6. Fijak M, Meinhardt A. The testis in immune privilege. Immunol Rev. 2006;213:66-81.

7. Garbuzenko E, Nagler A, Pickholtz D, et al. Human mast cells stimulate fibroblast proliferation, collagen synthesis and lattice contraction: a direct role for mast cells in skin fibrosis. Clin Exp Allergy. 2002;32:237-246.

8. Kimata M, Ishizaki M, Tanaka H, Nagai H, Inagaki N. Production of matrix metalloproteinases in human cultured mast cells: involvement of protein kinase C-mitogen activated protein kinase kinase-extracellular signal-regulated kinase pathway. Allergol Int. 2006;55:67-76.

9. Yamanaka K, Fujisawa M, Tanaka H, Okada H, Arakawa S, Kamidono S. Significance of human testicular mast cells and their subtypes in male infertility. Hum Reprod. 2000;15:1543-1547.

10. Apa DD, Cayan S, Polat A, Akbay E. Mast cells and fibrosis on testicular biopsies in male infertility. Arch Androl. 2002;48:337-344.

11. Chappel SC, Ramaley JA. Changes in the isoelectric focusing profile of pituitary follicle-stimulating hormone in the developing male rat. Biol Reprod. 1985;32(3):567-573.

12. Hou W, Hu J, Li Y, et al. Altered expression of NDRG2 in the testes of experimental rat model of cryptorchidism. Urology. 2010;75:985-991.

13. Johnsen SG. Testicular biopsy score count - a method for registration of spermatogenesis in human testes: normal values and results in 335 hypogonadal males. Hormones. 1970;1(1):2-25.

14. Sasagawa I, Yazawa H, Suzuki Y, et al. Reevaluation of testicular biopsies of males with nonobstructive azoospermia in assisted reproductive technology. Arch Androl. 2001;46(1):79-83.

15. Suskind A, Hayner-Buchan A, Feustel PJ, Kogan BA. Fibrosis correlates with detailed histological analysis of human undescended testes. BJU Int. 2008;101:1441-1445.

16. Nistal M, Santamaría L, Paniagua R. Mast cells in the human testis and epididymis from birth to adulthood. Acta Anat (Basel). 1984;119(3): 155-160.

17. Lu LF, Lind EF, Gondek DC, et al. Mast cells are essential intermediaries in regulatory T-cell tolerance. Nature. 2006;442:997-1002.

18. Gaytan F, Carrera G, Pinilla L, Aguilar R, Bellido C. Mast cells in the testis, epididymis and accessory glands of the rat: effects of neonatal steroid treatment. J Androl. 1989;10:351-358.

19. el Sayed SO, Dyson M. Histochemical heterogeneity of mast cells in rat dermis. Biotech Histochem. 1993;68:326-332. 
20. Algermissen B, Hermes B, Feldmann-Boeddeker I, Bauer F, Henz BM. Mast cell chymase and tryptase during tissue turnover: analysis on in vitro mitogenesis of fibroblasts and keratinocytes and alterations in cutaneous scars. Exp Dermatol. 1999;8:193-198.

21. Pinart E, Camps RM, Briz M, Bonet S, Egozcue J. Unilateral spontaneous abdominal cryptorchidism: structural and ultrastructural study of sperm morphology. Anim Reprod Sci. 1998;49:247-268.

22. Mechlin CW, Levesque J, Feustel P, Kogan BA. Mast cell numbers negatively correlate with fibrosis in cryptorchid testes. J Pediatr Urol. 2014;10(3):527-531

23. Agarwal S, Choudhury M, Banerjee A. Mast cells and idiopathic male infertility. Int J Fertil. 1987;32:283-286.

24. Maseki Y, Miyake K, Mitsuya H, Kitamura H, Yamada K. Mastocytosis occurring in the testes from patients with idiopathic male infertility. Fertil Steril. 1981;36:814-817.

25. Kollur SM, Pattankar VL, El Hag IA. Mast cells in testicular lesions. Ups J Med Sci. 2004;109:239-245.

26. Hashimoto J, Nagai T, Takaba H, Yamamoto M, Miyake K. Increased mast cells in the limiting membrane of seminiferous tubules in testes of patients with idiopathic infertility. Urol Int. 1988;43:129-132.

27. Nagai T, Takaba H, Miyake K, Hirabayashi Y, Yamada K. Testicular mast cell heterogeneity in idiopathic male infertility. Fertil Steril. 1992;57:1331-1336.

28. Hussein MR, Abou-DeifES, Bedaiwy MA, et al. Phenotypic characterization of the immune and mast cell infiltrates in the human testis shows normal and abnormal spermatogenesis. Fertil Steril. 2005;83:1447-1453.

29. Albrecht M, Ramsch R, Köhn FM, Schwarzer JU, Mayerhofer A. Isolation and cultivation of human testicular peritubular cells: a new model for the investigation of fibrotic processes in the human testis and male infertility. J Clin Endocrinol Metab. 2006;91:1956-1960.

30. Pinart E, Sancho S, Briz MD, Bonet S, Garcia N, Badia E. Ultrastructural study of the boar seminiferous epithelyum: changes in cryotorchidism. J Morphol. 2000;244:190-202.

31. Puxeddu I, Piliponsky AM, Bachelet I,Levi-Schaffer F. Mast cells in allergy and beyond. Int J Biochem Cell Biol. 2003;35(12):1601-1607.
32. Adam M, Schwarzer JU, Köhn FM, Strauss L, Poutanen M, Mayerhofer A. Mast cell tryptase stimulates production of decorin by human testicular peritubular cells: possible role of decorin in male infertility by interfering with growth factor signaling. Hum Reprod. 2011;26(10):2613-2625.

33. Mengel W, Zimmerman FA. Immunologic aspects of cryptorchidism. Urol Clin North Am. 1982;9:349-352.

34. Huff DS, Wu HY, Snyder HM 3rd, Hadziselimović F, Blythe B, Duckett JW. Evidence in favor of the mechanical (intrauterine torsion) theory over the endocrinopathy (cryptorchidism) theory in the pathogenesis of testicular agenesis. J Urol. 1991;146:630-631.

35. Zakaria O, Shono T, Imajima T, Suita S. Fertility and histological studies of the contralateral testes in two different intra- and extra-abdominal rat models of unilateral cryptorchidism. Br J Urol. 1998;82:574-577.

36. Kocak I, Dundar M, Hekimgil M, Okyay P. Assesment of germ cel apoptosis in cryptorchid rats. Asian J Androl. 2002;4:183-186.

37. Hatier R, Grignon G. Ultrastructural study of the Sertoli cell and the limiting membrane in the seminiferous tubule of the adult cryptorchid rat. Virchows Arch B Cell Pathol Inc Mol Pathol. 1986;52:305-318.

38. Kerr JB, Rich KA, de Kretser DM. Effects of experimental cryptorchidism on the ultrastructure and function of the Sertoli cell and peritubular tissue of the rat testis. Biol Reprod. 1979;21:823-838.

39. Jezek D, Banek L, Hittmair A, Pezerović-Panijan R, Goluza T, Schulze W. Mast cells in testicular biopsies of infertile men with 'mixed atrophy' of semineferous tubules. Andrologia. 1999;31:203-210.

40. Meineke V, Frungieri MB, Jessberger B, Vogt H, Mayerhofer A. Human testicular mast cells contain tryptase: increased mast cell number and altered distribution in the testes of infertile men. Fertil Steril. 2000; 74:239-244.

41. Welter H, Köhn FM, Mayerhofer A. Mast cells in human testicular biopsies from patients with mixed atrophy: increased numbers, heterogeneity, and expression of cyclooxygenase 2 and prostaglandin D2 synthase. Fertil Steril. 2011;96:309-313.
Drug Design, Development and Therapy

\section{Publish your work in this journal}

Drug Design, Development and Therapy is an international, peerreviewed open-access journal that spans the spectrum of drug design and development through to clinical applications. Clinical outcomes, patient safety, and programs for the development and effective, safe, and sustained use of medicines are a feature of the journal, which

\section{Dovepress}

has also been accepted for indexing on PubMed Central. The manuscript management system is completely online and includes a very quick and fair peer-review system, which is all easy to use. Visit http://www.dovepress.com/testimonials.php to read real quotes from published authors. 